\title{
Ihr Kinderlein kommet
}

\section{Iris Ritzmann}

Prof. Dr. med. et lic. phil., Mitglied der Redaktion Medizingeschichte

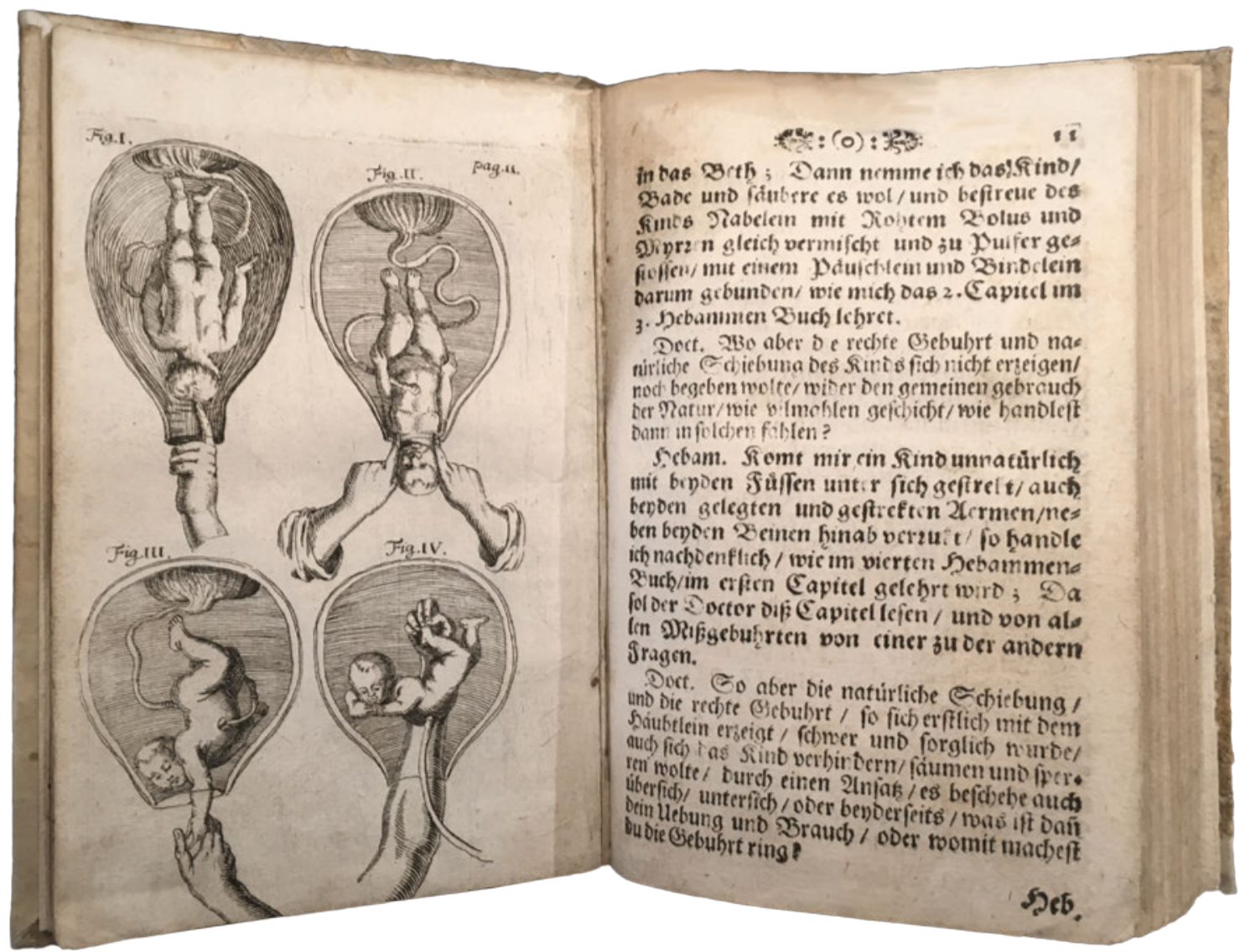

Johannes von Muralt, «Kinder-Büchlein», Figurae 1-4 vor Pagina 11. Erstausgabe, Zürich 1689, Sammlung Dr. Franz Käppeli.

"Kinder-Büchlein», so nannte der Stadtarzt von Zürich 1689 sein Werk. Es diente in erster Linie dem Hebammenunterricht. Im Grunde genommen umfasste es nichts anderes als den alten Hebammen-Katechismus der Stadt Zürich, der bereits 1554 im Pflichtenheft des Stadtarztes erwähnt wird. Dieser Katechismus kam als Lehrmittel und Prüfungskompendium zum Einsatz, funktionierte aber zugleich als verbindlicher Verhaltenskodex. Das korrekte geburtshilfliche Vorgehen wird hierbei in einem fiktiven Dialog zwischen Arzt und Hebamme vermittelt.

Auf den aufgeschlagenen Seiten lassen sich vier für jene Zeit typische, rundliche Gebärmütter erkennen, bewohnt von puppenhaften Föten. Die Hebamme sollte den kleinen Wesen kunstgerecht behilflich sein, ihr behagliches Zuhause zu verlassen. Die Kupferstiche zeigen der Reihe nach zuerst die Tastuntersuchung zur Feststellung der Kindslage, dann die Führung des Köpfchens bei Gesichtslage, anschliessend die Entwicklung der Geburt mit vorgelagertem Ärmchen und zuletzt die intrauterine Drehung des Kindes bei der gefürchteten Querlage.

Als das Werk erschien, war Johannes von Muralt (16451733) erst seit einem Jahr Stadtarzt in Zürich. Er hatte zuvor sowohl eine handwerklich-chirurgische und geburtshilfliche Ausbildung absolviert als auch Medizin und Anatomie studiert. Zurück in Zürich, führte der Herr Doktor - gegen massiven Widerstand - den anatomischen Unterricht für Chirurgen und Medizinstudenten ein. Sein Herz schlug für die Anatomie. Warum aber brachte er einen über hundertjährigen Text heraus? Wer das «Kinder-Büchlein» durchblättert, stösst auf eine Antwort: Zwischen die traditionellen geburtshilflichen Entbindungsbilder schmuggelte Muralt moderne anatomische Studien von sezierten Schwangeren für den heimlichen Unterricht der Hebammen ein.

Bildnachweis

Museum für medizinhistorische Bücher Muri (mmbm.ch) 